\title{
A BDNF sensitive mechanism is involved in the fear memory resulting from the interaction between stress and the retrieval of an established trace
}

\author{
Marcelo Giachero, Silvia G. Bustos, Gaston Calfa, and Victor A. Molina ${ }^{1}$ \\ IFEC-CONICET, Departamento de Farmacología, Facultad de Ciencias Químicas, Universidad Nacional de Córdoba, Haya de la Torre y \\ Medina Allende, Ciudad Universitaria, (5000) Córdoba, Argentina
}

\begin{abstract}
The present study investigates the fear memory resulting from the interaction of a stressful experience and the retrieval of an established fear memory trace. Such a combination enhanced both fear expression and fear retention in adult Wistar rats. Likewise, midazolam intra-basolateral amygdala (BLA) infusion prior to stress attenuated the enhancement of fear memory thus suggesting the involvement of a stress-induced reduction of the GABAergic transmission in BLA in the stress-induced enhancing effect. It has been suggested that, unlike the immediate-early gene Zif268 which is related to the reconsolidation process, the expression of hippocampal brain-derived neurotrophic factor (BDNF) is highly correlated with consolidation. We therefore evaluate the relative contribution of these two neurobiological processes to the fear memory resulting from the above-mentioned interaction. Intra-dorsal hippocampus (DH) infusions of either the antisense Zif268 or the inhibitor of the protein degradation (Clasto-Lactacystin $\beta$-Lactone), suggested to be involved in the retrieval-dependent destabilization process, did not affect the resulting contextual memory. In contrast, the knockdown of hippocampal BDNF mitigated the stress-induced facilitating influence on fear retention. In addition, the retrieval experience elevated BDNF level in DH at 60 min after recall exclusively in stressed animals. These findings suggest the involvement of a hippocampal BDNF sensitive mechanism in the stress-promoting influence on the fear memory following retrieval.
\end{abstract}

It is well known that after initial encoding, new threatening information undergoes a progressive stabilization process termed consolidation which requires de novo mRNA transcription and protein synthesis (Davis and Squire 1984; Goelet et al. 1986; McGaugh 2000; Dudai 2004). Upon retrieval, such a memory trace can reenter a transient labile state which requires the onset of a stabilization process dependent upon new protein synthesis referred to as reconsolidation (Nader et al. 2000; Sara 2000; Debiec et al. 2002). Although both processes require de novo mRNA and protein synthesis (Kida et al. 2002; Miller and Sweatt 2006; Tronson and Taylor 2007), it is well recognized that reconsolidation is not a faithful recapitulation of consolidation. In fact, nonoverlapping and distinctive mechanisms between consolidation and reconsolidation have been described in selected brain regions (Lee et al. 2004; Alberini 2005; Tronson and Taylor 2007; Lee 2008).

As previously noted (Dudai 2002; Hardt et al. 2010), retrieval is not a passive readout of prior experiences, rather retrieval can turn memory in a transient plasticity enabling dynamic modifications of the established memory trace (Sara 2000; Nader 2003; Duvarci and Nader 2004; Dudai 2006; Lee 2009); however, it should be noted that retrieval does not always lead to a reconsolidation process (Gisquet-Verrier and Riccio 2012). Under certain circumstances, for instance, new information can be updated into the original trace and its strength can be significantly modified (Lee 2008, 2010; Rodriguez-Ortiz et al. 2008; Hupbach et al. 2009). Hence, the combination of the retrieval experience and stress is functionally suitable to rewrite emotional memories read-

\footnotetext{
${ }^{1}$ Corresponding author

E-mail vmolina@fcq.unc.edu.ar

Article is online at http://www.learnmem.org/cgi/doi/10.1101/lm.029306.112.
}

justing the trace to contemporary environmental conditions (Schiller et al. 2010). In this line of reasoning, a pre-retrieval environmental threat unrelated to the cognitive task might be incorporated into the fear memory trace by means of an updating mechanism which is later stabilized by reconsolidation. Alternatively, due to the fact that the retrieval of a fear memory is an aversive experience by itself (Dudai 2002), memory retrieval and its behavioral expression can be affected by an unrelated stressful experience without necessarily being updated. In fact, extensive findings have shown that prior stress exposure promotes negative emotional reactions to future encounters with an unrelated mild aversive stimulation (Martijena et al. 2002; Calfa et al. 2006; Bignante et al. 2008), such as the retrieval experience of a previously modest learning procedure.

A vast literature supports the view that emotionally arousing events affect fear memory formation (Roozendaal 2002; Payne et al. 2007; Roozendaal et al. 2009). In line with this view, a substantial number of reports have revealed that diverse stressful experiences prior to learning promote the emergence of robust emotional memories (Cordero et al. 2003; Rodriguez Manzanares et al. 2005). However, few studies so far have addressed the study of the long-term influence of an unrelated threatening experience on the resulting memory following the retrieval of an established trace.

Consequently, one of the aims of the present study was to investigate the fear behavior resulting from the interaction between a stressful experience and the retrieval of a fear memory trace. Importantly, since a selective mechanism of memory consolidation and reconsolidation in the dorsal hippocampus (DH) has been previously reported in contextual fear memories (Lee et al. 2004), the second aim of this study was to analyze the relative contribution of the neurobiological mechanisms underlying these two processes in the fear memory resulting from such interaction. 


\section{Results}

\section{Experiment 1}

Stress exposure prior to retrieval of a consolidated trace strengthens the expression and retention of the resulting contextual fear memory

In order to determine whether stress exposure influences fear memory at the time of retrieval, a group of animals was randomly selected, placed in a conditioning chamber (context A [CA]), and subjected to a single footshock protocol (weak training procedure; CA unsignaled footshock [CA-US]), or no footshock administration (CA-noUS). After $24 \mathrm{~h}$ the rats from both groups were once again randomly selected and exposed to the stressful experience or not exposed to this event (see Material and Methods). Subsequently, freezing behavior during reexposures to the associated context (CA) was assessed during test 1 and test 2 (Fig. 1A).

A Student's $t$-test for the time spent freezing during the preshock period showed a nonsignificant effect between the two groups $(P=0.961)$. The mean \pm SEMs of the percentage of freezing from both groups were CA-US, $10.37 \pm 1.22$ and CA-noUS, $10.29 \pm 1.31$.

During the post-shock period, a Student's $t$-test analysis revealed a significant effect between CA-US vs. CA-noUS $(P<$ 0.001 ) where the animals that received the shock showed a significant increased freezing response during the post-shock period (percentage of freezing [mean + SEM] CA-US, $29.31 \pm 1.73$ ) in

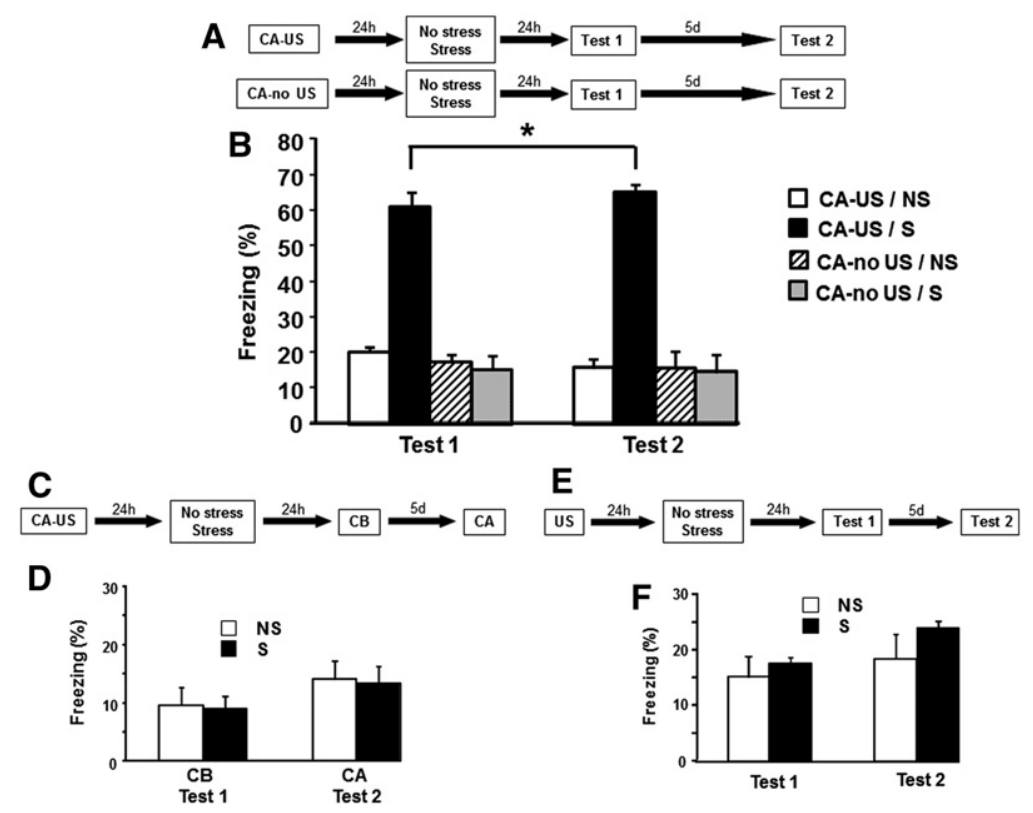

Figure 1. The interaction between stress and the retrieval of a consolidated trace enhances the resulting fear memory. (A) Schematic representation of the experimental design. (B) Bar graph showing the freezing response denoted in animals at 1 and $6 \mathrm{~d}$ after the exposure to a stressful experience. Stressed and control nonstressed animals were formerly conditioned or exposed to the context without receiving the shock stimulus. Data are expressed as mean \pm SEM percentage of freezing spent during the test ( $n=6-8$ rats per group). $\left(^{*}\right) P<0.05$ compared to the rest of the experimental groups (repeated measures ANOVA, Bonferroni post-hoc test). (C) Schematic representation of the experimental design. (D) Bar graph showing the freezing response denoted in animals exposed to the nonassociated chamber (context CB) (test 1) and CA (test 2) after training in stressed and control nonstressed animals. Data are expressed as mean \pm SEM percentage of freezing spent during the test ( $n=6-8$ rats per group). $P>0.05$ in all interactions (repeated measures ANOVA). (E) Schematic representation of the experimental design. $(F)$ Bar graph showing the freezing response $1 \mathrm{~d}$ and $11 \mathrm{~d}$ after stress in animals that were previously subjected to an immediate footshock deficit protocol. Data are expressed as mean \pm SEM percentage of freezing spent during the test $(n=6-8$ rats per group). $P>0.05$ in all interactions (repeated measures ANOVA). comparison to the group that was not footshocked (CA-noUS,

A repeated measures ANOVA for the freezing behavior response during test 1 and test 2 showed a significant effect of training $\left(F_{(1,42)}=181.01, P<0.05\right)$, stress $\left(F_{(1,42)}=76.208, P<0.05\right)$, training $\times$ stress $\left(F_{(1,42)}=92.572, P<0.05\right)$, test trial as repeated measures $\left(F_{(1,42)}=6.943, P<0.05\right)$, and test trial $\times$ training $\left.F_{(1,42)}=4.997, P=0.034\right)$. However, there was no statistically significtion between test trial $\times$ stress $\left(F_{(1,42)}=0.128, P=\right.$ $0.723)$ and training $\times$ stress $\times$ test trial $\left(F_{(1,42)}=0.073, P=0.788\right)$. similar. From the relevant statistical information, this training rats. Interestingly, stressed rats tested in the associated context exhibited higher levels of freezing as compared to those of the remaining experimental groups at both test 1 and test $2(P<0.05)$. both fear expression and fear retention, indicating that the combination of fear conditioning, stress, and the recall session leads (test 1).

To test whether the promoting effect of stress on fear memois specific to the associated context, a group of animals was subthey were subjected to restraint. After a further $24 \mathrm{~h}$, the animals were exposed to a novel nonassociated context (CB) and the freezing behavior was assessed. Five days later, animals were relocated in the CA and their subsequent freezing behavior was evaluated (Fig. 1C).

A repeated measures ANOVA analysis revealed a nonsignificant effect of stress $\left(F_{(1,13)}=0.024, P=0.878\right)$ and test trial as repeated measures $\left(F_{(1,13)}=\right.$ 3.917, $P=0.069)$, and of stress $\times$ test trial $\left(F_{(1,13)}=0.003, P=0.958\right)$ (Fig. $1 D)$. Thus, minimal fear response was evident when animals were located in the novel nonassociated context and later on in the conditioning context, which indicates that the stress-induced enhancing effect previously described is contingent upon the retrieval of the associated context, and it is not produced by a simple fear generalization. In addition, stressed rats showed low levels of freezing during test 2 , showing that for the promoting influence to take place, the retrieval experience (test 1) should be performed at least $1 \mathrm{~d}$ after stress exposure.

It could be argued that the greater fear expression and retention in stressed animals observed in the first experiment could be induced by a sensitized response to the restraint session resulting from the nonassociated previous footshock experience. To control this possibility, all rats were subjected to the immediate footshock deficit protocol (see Material and Methods). One day after the footshock experience, the animals were either submitted to the stress experience or retained in their home cages without manipulation. After $1 \mathrm{~d}$ (test 1) and $5 \mathrm{~d}$ (test 2) rats were reexposed to CA (Fig. 1E). 
A repeated measures ANOVA analysis revealed a significant effect of the test trial as repeated measures $\left(F_{(1,14)}=11.514, P=\right.$ $0.0043)$. However, a nonsignificant effect was observed in both the stress exposure $\left(F_{(1,14)}=1.618, P=0.224\right)$ and the interaction between stress $\times$ test trial $\left(F_{(1,14)}=0.015, P=0.903\right)$ (Fig. $\left.1 F\right)$. Although a significant effect of test trial was observed, the freezing response between stressed and nonstressed rats in any trial $(P>$ 0.05 ) was not different. In fact, stressed and nonstressed rats displayed similar levels of freezing in both tests, thus supporting the view that the higher freezing level observed in stressed animals was not due to a sensitized response resulting from a previous nonassociative footshock experience. Therefore, it becomes evident that an associated trace should be formed in order for the interaction between stress and retrieval to take place.

\section{Experiment 2}

\section{Intra-basolateral amygdala (BLA) infusion of midazolam (MDZ) prior to stress attenuates the promoting influence of restraint and retrieval on contextual fear memory}

It has been suggested that the activation of GABAergic sites by local MDZ infusion into the BLA prior to the environmental challenge prevents the behavioral reactions of stress exposure, including the facilitating influence on the formation of fear memory (Rodriguez Manzanares et al. 2005; Maldonado et al. 2011). Thus, the current experiment investigates the effect of MDZ intra-BLA prior to the restraint session on the resulting fear memory after retrieval. To this end, bilateral cannulas targeting the BLA were implanted; after $1 \mathrm{wk}$ all animals received the weak training procedure (CA-US) as in the previous experiments. One day after conditioning, animals were randomly saline (SAL) or MDZ intra-BLA administered. After $10 \mathrm{~min}$ a group of rats randomly selected was exposed to the stressful event (S) or remained without manipulation (NS). One and $6 \mathrm{~d}$ after restraint, all rats were
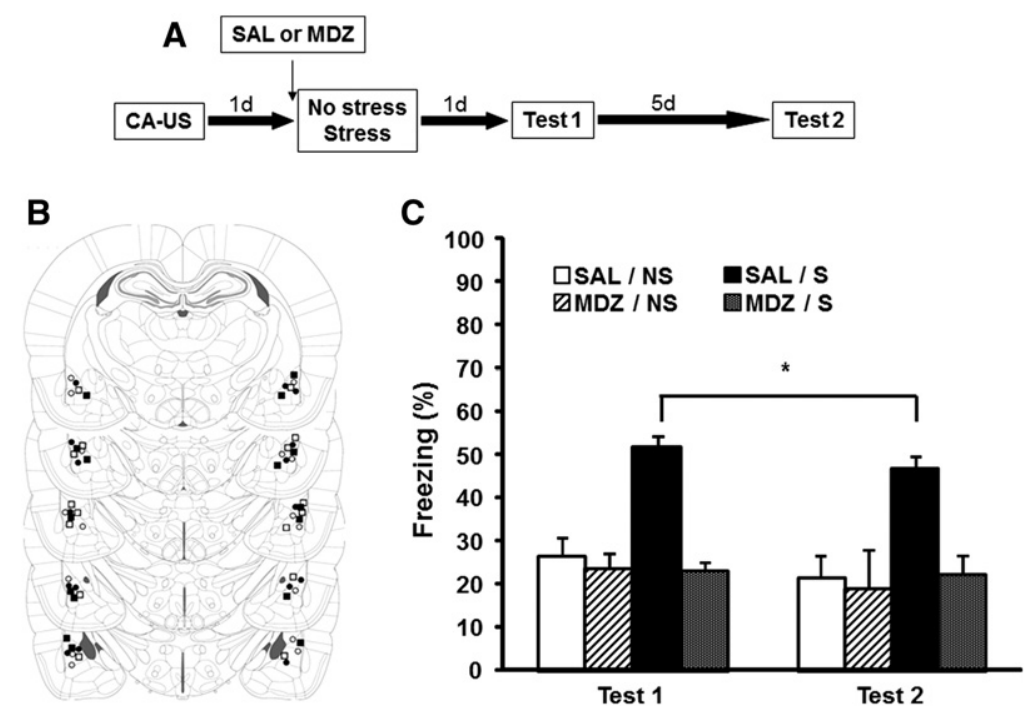

Figure 2. MDZ intra-BLA infusion prior to stress affects the expression and retention of the resulting fear memory. (A) Schematic representation of the experimental design. (B) Schematic drawings of coronal sections showing the location of the cannula placement in BLA (adapted from Paxinos and Watson 1986 with permission from Elsevier (C) 1986); (black filled circles) MDZ/S, (unfilled circles) MDZ/NS, (black filled squares) SAL/S, (unfilled squares) SAL/NS. (C) Freezing behavior response observed in the conditioned context at test 1 and test 2 in rats that either received intra-BLA administration of MDZ or SAL 10 min prior to restraint. Data are expressed as mean \pm SEM percentage of freezing spent during the tests ( $n=8$ rats for all groups). $\left(^{*}\right) P<0.05$ compared to the rest of the experimental groups (repeated measures ANOVA, Bonferroni post-hoc test). reexposed to the associated context and their freezing assessed (Fig. 2A,B).

The percentage of freezing spent during pre-shock and postshock are as follows: pre-shock CA-US (mean \pm SEM), $5.19 \pm$ 0.91 ; post shock CA-US, $25.55 \pm 1.95$.

A repeated measures ANOVA for the time spent freezing during both test 1 and test 2 revealed a significant effect of drug treatment $\left(F_{(1,27)}=55.657, P<0.05\right)$, stress $\left(F_{(1,27)}=72.72, P<0.05\right)$, drug treatment $\times$ stress interaction $\left(F_{(1,27)}=63.972, P<0.05\right)$, and test trial as repeated measures $\left(F_{(1,27)}=4.685, P<0.039\right)$. However, a nonsignificant interaction was observed between test trial $\times$ drug treatment $\left(F_{(1,27)}=1.577, P=0.22\right)$, test trial $\times$ stress $\left(F_{(1,27)}=1.086, P=0.306\right)$, and drug treatment $\times$ stress $\times$ test trial $\left(F_{(1,27)}=0.378, P=0.543\right)$ (Fig. 2C). Thus, the statistically relevant information reveals a higher freezing behavior of stressed animals with intra-BLA SAL at both test 1 and test 2 . Interestingly, such a behavioral response was prevented by the local MDZ infusion. An equivalent fear response was observed between unstressed animals administered MDZ intra-BLA and unstressed animals with SAL intra-BLA infusion. The findings of the current experiment indicate that MDZ intra-BLA prior to restraint prevents the promoting influence of stress and retrieval on the resulting fear memory.

\section{Experiment 3}

\section{Intra-DH infusion of Zif268 anti-sense (Zif268 ASO) does not affect the} contextual fear memory following retrieval and stress

There is evidence of a double dissociable cellular mechanism for consolidation and reconsolidation in the hippocampus for the contextual fear memory (Lee et al. 2004). Thus, the expression of the hippocampal Zif268 following contextual memory reactivation has been closely associated with a reconsolidation-like mechanism (Lee et al. 2004). Therefore, if stress-induced memory strengthening involves reconsolidation, knocking down Zif268 in the DH should impair the promoting influence of stress after interacting with the fear memory retrieval. To explore this possibility, DH-cannulated animals were subjected to the same weak training procedure (CA-US) as in Experiment 1, and subsequently a group of animals was randomly assigned to the stress condition (S) or remained without manipulation (NS) and the following day both groups $S$ and NS were randomly Zif268 ASO or missense (MSO) infused 90 min prior to retrieval (test 1). Fear behavior was determined during both test 1 and test 2 (Fig. 3A).

The percentages of freezing spent during pre-shock and post-shock are as follows: pre-shock CA-US (mean \pm SEM), $3.8 \pm 1.31$; post-shock CA-US: $28.4 \pm 1.78$.

A repeated measures ANOVA for the time spent freezing during both test 1 and test 2 revealed a significant effect of stress $\left(F_{(1,26)}=146.92, P<\right.$ $0.05)$ and test trial as repeated measures $\left(F_{(1,26)}=6.414, P=0.017\right)$. However, a nonsignificant effect was observed in drug treatment $\left(F_{(1,26)}=\right.$ 1.338, $P=0.258)$, stress $\times$ drug treatment $\left(F_{(1,26)}=0.764, P=0.39\right)$, test 
A

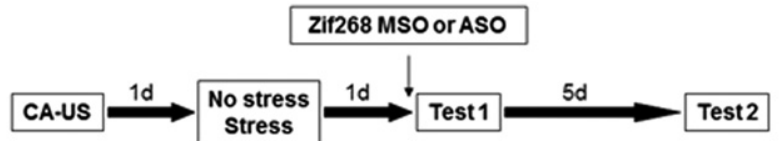

B

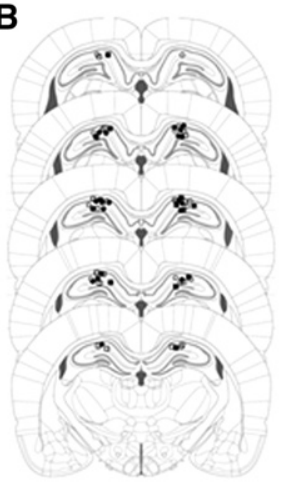

C

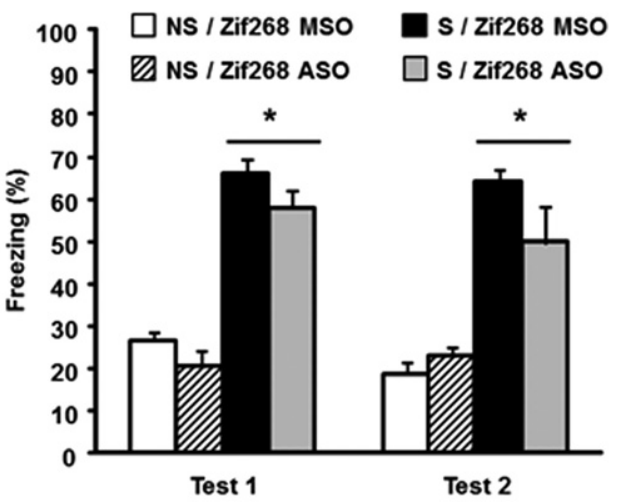

D

Zif268 MSO or ASO

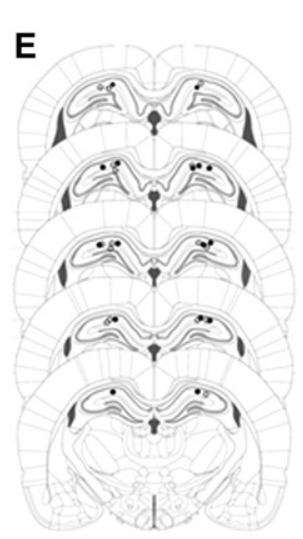

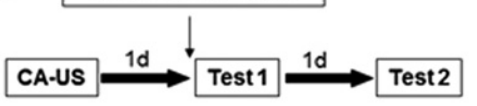

$\mathbf{F}$

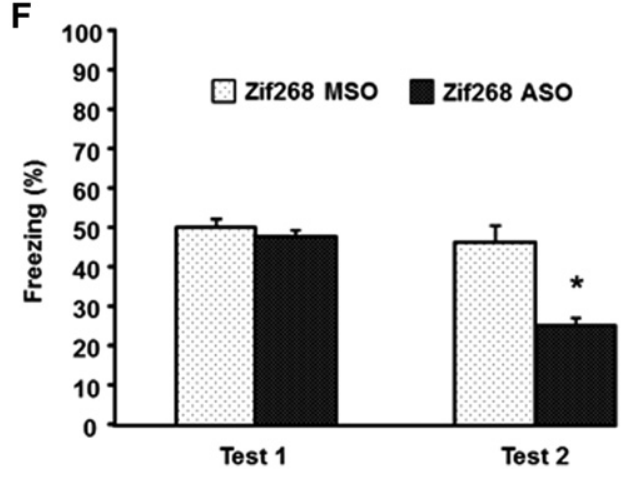

Figure 3. Influence of Zif268 antisense in $\mathrm{DH}$ on the resulting contextual fear memory following stress and retrieval. (A) Schematic representation of the experimental design. (B) Graphic drawings of coronal sections showing the location of the cannula placement in $\mathrm{DH}$ (adapted from Paxinos and Watson 1986 with persmission from Elsevier (c) 1986); (black filled circles) NS/Zif268 ASO, (unfilled circles) S/Zif268 ASO, (black filled squares) NS/Zif268 MSO, (unfilled squares) S/Zif268 MSO. (C) Freezing behavior observed at test 1 and test 2 in animals with intra-DH Zif268 ASO or MSO administration prior to test 1 . Data are expressed as mean \pm SEM percentage of freezing spent during both tests ( $n=8$ rats for all groups). ( $\left.{ }^{*}\right) P<0.05$ compared to the rest of the experimental groups (repeated measure ANOVA, Bonferroni post-hoc test). (D) Schematic representation of the experimental design. (E) Graphic drawings of coronal sections showing the location of the cannula placement in DH (adapted from Paxinos and Watson 1986 with permission from Elsevier (1) 1986); (black filled circles) Zif268 MSO, (unfilled circles) Zif268 ASO. (F) The freezing exhibited in both tests by control unstressed rats with intra-DH Zif268 ASO or MSO administration. Animals were previously subjected to a classic fear training procedure, three footshocks instead of a single shock-context experience ( $n=8$ rats for all groups). $\left(^{*}\right) P<0.05$ compared to the rest of the experimental groups (repeated measure ANOVA, Bonferroni post-hoc test).

trial $\times$ stress $\left(F_{(1,26)}=0.967, P=0.334\right)$, test trial $\times$ drug treatment $\left(F_{(1,26)}=1.937, P=0.176\right)$, and stress $\times$ drug treatment $\times$ test trial $\left(F_{(1,26)}=3.297, P=0.081\right)$. As shown in Figure $3 \mathrm{C}$, stressed animals either infused with Zif268 ASO or MSO in the DH showed a higher fear response in both trials as compared to unstressed animals $(P<0.05)$. Hence, the knockdown of Zif268 did not affect stress-induced memory strengthening.

It is important to note that Zif268 knockdown does not affect the behavioral performance of nonstressed animals. This lack of effect could be obscured by the low level of fear exhibited by non- stressed animals during retrieval. We therefore examined the effect of the Zif268 ASO on control rats that had been previously subjected to a stronger fear training (three footshocks instead of the single shock-context experience) (Fig. 3D).

The percentages of freezing spent during pre-shock and post-shock are as follows: pre-shock CA-US (mean \pm SEM), $23.15 \pm 3.28$; post-shock CAUS, $88 \pm 3.73$.

A repeated measures ANOVA, considering the test trial as repeated measures, showed a significant effect of drug treatment $\left(F_{(1,14)}=23.562, P=\right.$ $0.00026)$, test trial $\left(F_{(1,14)}=34.645\right.$, $P<0.05)$, and drug treatment $\times$ test trial $\left(F_{(1,14)}=17.824, P=0.00085\right)$. All rats, either infused with the Zif268 ASO or MSO, exhibited considerable freezing scores during test 1 . Such an elevated fear response was attenuated during test 2 in animals with intraDH Zif268 ASO $(P<0.05)$ (Fig. 3F). Consistent with previous findings, knocking down hippocampal Zif268 impaired memory retention probably through reconsolidation blockade in control unstressed rats (Lee et al. 2004).

\section{Experiment 4}

\section{Intra-DH clasto-lactacystine- $\beta$-lactone $(\beta-$ lac) administration does not affect the contextual fear memory following retrieval and stress}

Strengthening contextual-fear memory by an additional learning trial requires the occurrence of a retrieval-induced destabilization process (Lee 2008). Such a process is dependent on hippocampal synaptic protein degradation (Lee et al. 2008). Therefore, if retrievalinduced fragility is a prerequisite for stress-induced memory strengthening following retrieval, impairing protein degradation by intra-DH $\beta$-lac infusion should prevent the elevation of fear in stressed animals. To investigate this possibility, DH cannulated rats were subjected to the same weak training procedure (CA-US) as in Experiment 1 , and subsequently a group of animals was randomly assigned to the stress condition or remained without manipulation, and $1 \mathrm{~d}$ later reexposed to the training chamber. Immediately afterward, the animals were randomly $\beta$-lac or SAL intra-DH administered. Freezing behavior was evaluated during test 1 and test 2 (Fig. 4A).

The percentage of freezing spent during pre-shock and postshock are as follows: pre-shock CA-US (mean \pm SEM), $2.43 \pm$ 0.81 ; post-shock CA-US, $25.25 \pm 2.42$.

A repeated measures ANOVA for the time spent freezing during both test 1 and test 2 revealed a significant effect of stress $\left(F_{(1,24)}=78.926, P<0.05\right)$ and test trial as repeated measures 
A

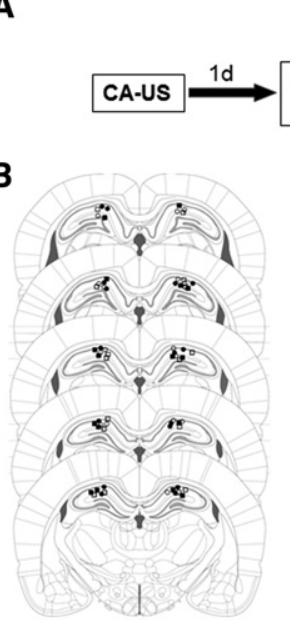

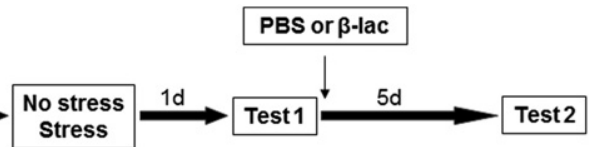

C

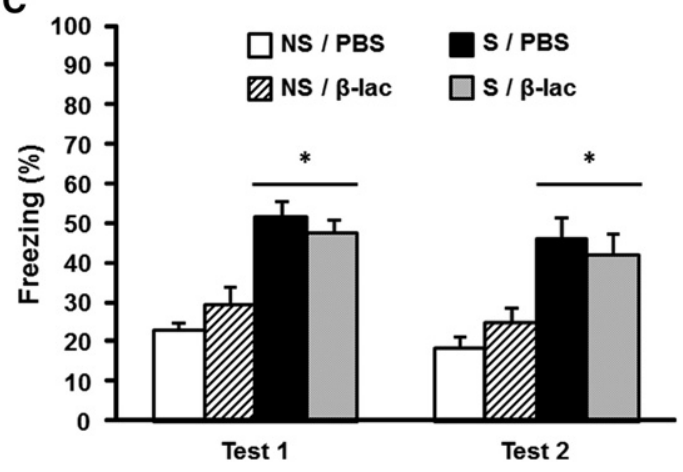

Figure 4. Effect of intra-DH $\beta$-lac infusion on the resulting contextual fear memory following stress and retrieval. $(A)$ Schematic representation of the experimental design. (B) Schematic drawings of coronal sections showing the location of the cannula placement in DH (adapted from Paxinos and Watson 1986 with permission from Elsevier (C) 1986); (black filled circles) NS/ $\beta$-lac, (unfilled circles) S/ $\beta$-lac, (black filled squares) NS/PBS, (unfilled squares) S/PBS. (C) Freezing behavior observed at both tests in animals that received intra-DH $\beta$-lac administration immediately after test 1 . Data are expressed as mean \pm SEM percentage of freezing spent during the test ( $n=8$ rats for all groups). ( $\left.{ }^{*}\right)$ $P<0.05$ compared to the rest of the experimental groups (repeated measures ANOVA, Bonferroni post-hoc test).

$\left(F_{(1,24)}=4.729, P=0.04\right)$. However, a nonsignificant effect was observed by drug treatment $\left(F_{(1,24)}=0.003, P=0.959\right)$, drug treatment $\times$ stress $\left(F_{(1,24)}=1.564, P=0.223\right)$, test trial $\times$ stress $\left(F_{(1,24)}=0.134, P=0.717\right)$, test trial $\times$ drug treatment $\left(F_{(1,24)}=\right.$ $0.069, \quad P=0.794)$, and drug treatment $\times$ stress $\times$ test trial $\left(F_{(1,24)}=0.041, P=0.841\right)$. This analysis shows that stressed rats with intraDH vehicle or $\beta$-lac infusions exhibit higher freezing during both test 1 and test 2 as compared to nonstressed rats either infused with vehicle or $\beta$-lac (Fig. 4C). Hence, the inhibition of the retrieval-induced destabilization process does not prevent the promoting influence of stress on fear memory.

\section{Experiment 5}

The intra-DH infusion of BDNF ASO impairs the enhancement of the fear memory resulting after retrieval and stress

Within the framework of a hippocampal double dissociable mechanism for consolidation and reconsolidation of contextual fear memory (Lee et al. 2004), it has been reported that the BDNF expression in DH highly correlates with consolidation but not with a reconsolidation process (Lee et al. 2004) In order to test a BDNF role in the stress-induced promoting influence on fear memory after retrieval, $\mathrm{DH}$ cannulated rats were subjected to the same weak training procedure (CA-US) as in Experiment 1, and subsequently a

A
B

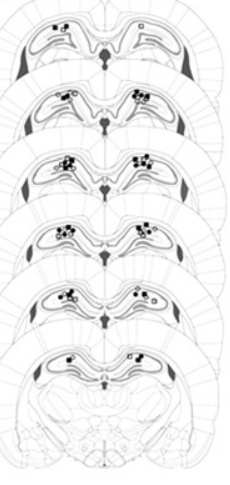

group of animals was randomly assigned to the stress condition or remained without manipulation. After 1 $\mathrm{d}$, rats randomly selected received intra-DH BDNF ASO or MSO 90 min prior to the exposure to the CA (test 1 ) and their fear evaluated. Five days later, all rats were relocated in the CA to assess freezing during test 2 (Fig. 5A).

The percentage of freezing spent during pre-shock and post-shock are as follows: pre-shock CA-US (mean \pm SEM), $3.06 \pm 0.98$; post-shock CA-US, $25.28 \pm 2.13$.

A repeated measures ANOVA for the time spent freezing during both test 1 and test 2 indicated a significant effect of stress $\left(F_{(1,28)}=100.83, P<\right.$ 0.05), drug treatment $\left(F_{(1,28)}=8.577\right.$, $P=0.007), \quad$ stress $\times$ drug treatment $\left(F_{(1,28)}=13.306, P=0.001\right)$, test trial as repeated measures $\left(F_{(1,28)}=41.445\right.$, $P<0.05)$, test trial $\times$ stress $\left(F_{(1,28)}=\right.$ 9.817, $P=0.004)$, test trial $\times$ drug treatment $\left(F_{(1,28)}=31.697, P<0.05\right)$, and stress $\times$ drug treatment $\times$ test trial $\left(F_{(1,28)}=21.859, \quad P<0.05\right)$. Furthermore, Bonferroni post-hoc analysis indicated that stressed animals infused intra-DH with BDNF MSO or ASO exhibited a higher freezing score at test 1 compared to those unstressed rats either administered with BDNF ASO or MSO $(P<$ 0.05). Interestingly, stressed animals with $B D N F \mathrm{MSO}$ intra-DH infusion exhibited a higher freezing at test 2 compared to those with the BDNF ASO intra-DH infusion and to unstressed rats either ad-

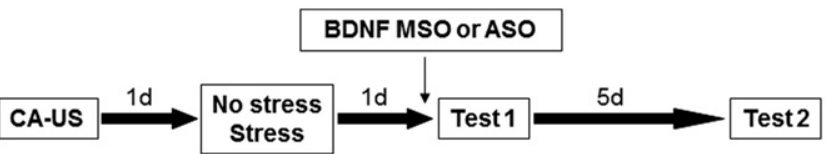

C

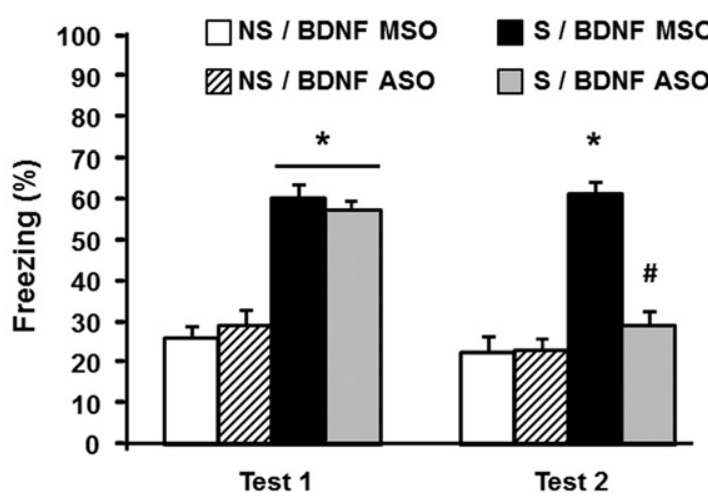

Figure 5. Intra-DH BDNF antisense infusion affects stress-induced promoting influence on fear memory after retrieval. (A) Schematic representation of the experimental design. (B) Schematic drawings of coronal sections showing the location of the cannula placement in $\mathrm{DH}$ (adapted from Paxinos and Watson 1986 with permission from Elsevier (C) 1986); (black filled circles) NS/BDNF ASO, (unfilled circles) S/BDNF ASO, (black filled squares) NS/BDNF MSO, (unfilled squares) S/BDNF MSO. (C) Freezing behavior observed at both tests in animals that received intra-DH BDNF ASO or the MSO administration previous to the test 1 . Data are expressed as mean \pm SEM percentage of freezing spent during the test ( $n=8$ rats for all groups). $\left(^{*}\right) P<0.05$ compared to the rest of the experimental groups (repeated measures ANOVA, Bonferroni post-hoc test). 
ministered with BDNF ASO or MSO ( $P<0.05$ ) (Fig. 5C). Hence, these findings support the role of hippocampal BDNF in the facilitating influence on contextual fear memory following the interaction of stress and fear memory retrieval.

\section{Experiment 6}

Retrieval of contextual fear memory in stressed animals increases BDNF level in the $\mathrm{DH}$

Given that knocking down BDNF in DH prevented the enhanced fear response in stressed animals, we enquired whether retrieval following stress elicits selective changes on BDNF levels in DH. Toward this goal, we have analyzed the time course of BDNF protein levels in DH following retrieval. Rats were subjected to the weak-trained procedure as Experiment 1, and then subjected to the stress experience or remained without manipulation. After $24 \mathrm{~h}$, all animals were reexposed to the associated environment and sacrificed at 0, $30 \mathrm{~min}, 60 \mathrm{~min}$, and $120 \mathrm{~min}$ (Fig. 6A).

The percentage of freezing spent during pre-shock and postshock are as follows: pre-shock CA-US (mean \pm SEM), $5.12 \pm$ 0.82; post-shock CA-US, $27.85 \pm 2.41$.

A one-way ANOVA analysis for BDNF levels at the different time points reflected a significant effect of stress and time $\left(F_{(7,32)}=12.656, P<0.05\right)$. A Bonferroni post-hoc test revealed a higher BDNF level in DH of stressed animals only at 60 min after recall $(P<0.05)$ (Fig. 6B). This finding is consistent with the view that the promoting influence of stress on contextual fear memory is related to an increase of hippocampal BDNF expression.

To further confirm that the behavioral effects induced by the $B D N F$ ASO correlate with BDNF levels, all animals were weaktrained and subsequently stressed. The following day, 90 min prior to test $1, B D N F A S O$ or $M S O$ were $\mathrm{DH}$ infused. All animals were sacrificed $60 \mathrm{~min}$ later and BDNF levels assessed (Fig. 6C).

The percentage of freezing spent during pre-shock and postshock are as follows: pre-shock CA-US (mean \pm SEM), $5.35 \pm$ 0.96; post-shock CA-US, $25.84 \pm 1.82$.

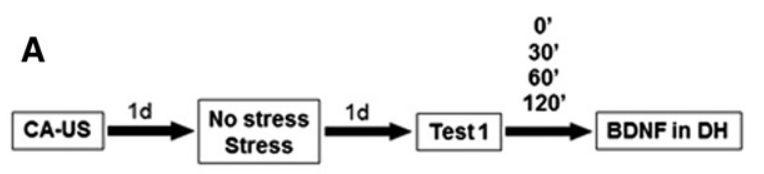

B

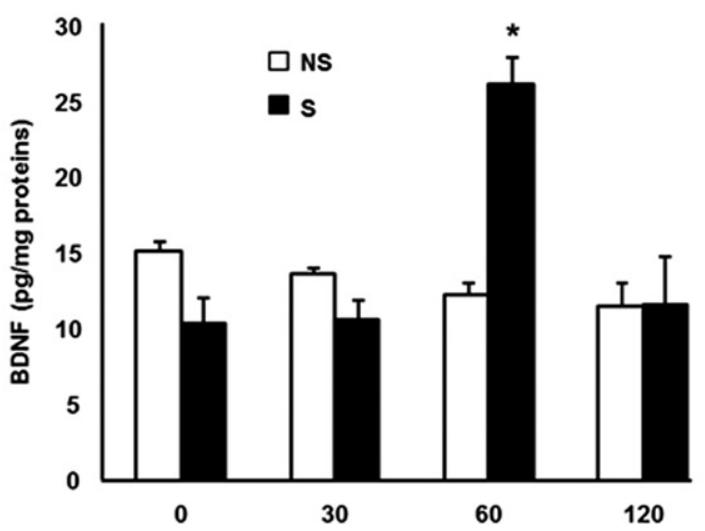

Lower BDNF levels were observed in the BDNF ASO animals as compared to BDNF MSO animals ( $P<0.05$, Student's $t$-test) (Fig. $6 \mathrm{E})$. Therefore, these findings support the role of the hippocampal BDNF in such a stress-induced strengthening influence.

\section{Discussion}

The present study has shown that the interaction of a stressful experience and the retrieval of an established memory trace strengthen the resulting contextual fear memory. Such a promoting influence is not only evident during retrieval (test 1) but also noticeable after $5 \mathrm{~d}$ (test 2 ). In addition, since no effect was detectable when stressed animals were exposed to a different environment, an unspecific generalization of fear can be discarded, confirming that exposure to the associated context is a requirement for the promoting influence to take place. Importantly, stress only magnified the fear response in those rats subjected to the associated learning, indicating that the stress-induced promoting influence is crucially dependent on the previous context-US association. Moreover, a sensitized response to restraint due to the nonassociated past-footshock experience is unlikely since no stress-induced effect was evident when animals had previously undergone immediate footshock deficit, a procedure which is unable to produce contextual fear learning (Landeira-Fernandez et al. 2006).

Previous reports have shown that both stress exposure and stress-related hormone administration close to testing impair memory retrieval. Such an effect is temporary and unobservable at longer intervals since it is correlated with elevated plasma corticosterone levels at the time of testing (de Quervain et al. 1998, 2003; Roozendaal 2002; Cai et al. 2006; Atsak et al. 2012). However, in the current protocol, the fact that retrieval was performed $1 \mathrm{~d}$ after restraint excludes the involvement of secretion of stress-related hormones in the facilitating effect following stress and retrieval. This view does not exclude an initial role of stressrelated hormones shortly after stress exposure in our experimental paradigm.
C

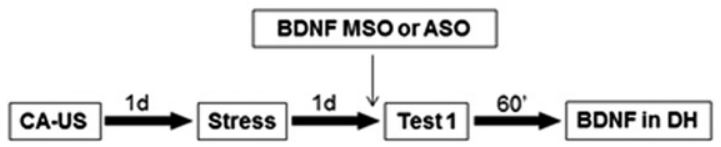

D

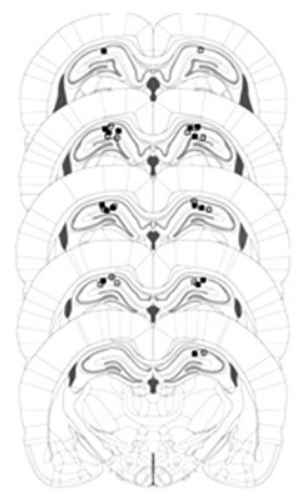

E

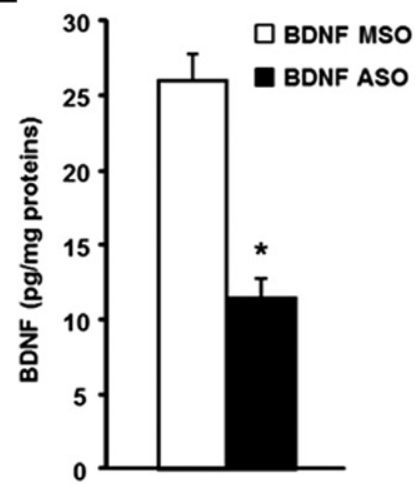

Figure 6. BDNF Levels in DH after stress and retrieval. $(A)$ Schematic representation of the experimental design. (B) Bar graph indicating BDNF levels (mean \pm SEM) at different time points after memory retrieval in stressed and nonstressed animals $\left(\left[{ }^{*}\right] P<0.05\right.$ compared to the rest of the experimental groups, one-way ANOVA, Bonferroni post-hoc test). (C) Schematic representation of the experimental design. (D) Schematic drawings of coronal sections showing the location of the cannula placement in DH (adapted from Paxinos and Watson 1986 with permission from Elsevier 1986 ); (black filled squares) BDNF MSO, (unfilled squares) BDNF ASO. (E) Bar graph indicating BDNF levels (mean \pm SEM) at 60 min after retrieval in stressed animals previously administered intra-HD with BDNF ASO or MSO ( $n=5$ rats per group; $\left[{ }^{*}\right] P<0.05$ Student's $t$-test). 
As previously noted, nonoverlapping mechanisms in the DH have been suggested between consolidation and reconsolidation in contextual fear memory (Lee et al. 2004; Alberini 2005; Tronson and Taylor 2007). Whereas, reconsolidation requires hippocampal Zif268 expression, the consolidation process is suggested to be dependent on hippocampal BDNF (Lee et al. 2004). What is more, Lee (2008), using a different procedure to that performed in the current study, showed that an additional shock presentation during memory reactivation was updated in the original memory by a reconsolidation mechanism dependent on hippocampal Zif268 expression, but not on BDNF production.

It has been proposed that fear memory reconsolidation consists of two closely associated phases, a reactivation-dependent destabilization process requiring protein degradation (Lee 2008) and a protein synthesis dependent restabilization phase (Nader et al. 2000; Alberini 2011). Our results indicate that the intraDH Zif268 ASO does not modify the resulting fear memory trace after stress and retrieval. Moreover, protein degradation by the ubiquitin/proteosome underlies destabilization after fear memory reactivation (Lee 2008). Consistently, hippocampal infusion of a proteasome inhibitor before reactivation prevents the onset of memory reconsolidation (Lee 2008) and the updating of new information in a consolidated fear memory (Lee 2008). The current findings reveal that the blockade of protein degradation by means of $\beta$-lac intra-DH infusions did not affect the resulting contextual memory following the combination of stress and the retrieval experience, suggesting that destabilization after retrieval is not a prerequisite for the promoting influence of stress on the resulting trace. Therefore, if the retrieval-induced Zif268 expression and destabilization-induced protein degradation are both essential processes for the occurrence of reconsolidation, as previously suggested (Lee et al. 2004, 2008; Rudy 2008), the involvement of a reconsolidation mechanism in the stress-induced memory strengthening observed in this study seems less likely.

Using contextual fear protocols, some authors indicate that fear learning regulates the expression of Zif268 mRNA in the lateral amygdala (Malkani and Rosen 2000), whereas others suggest a role of this molecule in the retrieval experience but not in the acquisition (Hall et al. 2000, 2001). Recently, Maddox et al. (2011), using an auditory Pavlovian fear protocol, indicated that Zif268 response in LA is required for both new association and reactivation of consolidated fear memories (Maddox et al. 2011). The reason for these discrepancies in the amygdala nuclei remains unclear; however, it has been suggested that such controversies depend on the context properties since the amygdala modulates the contextual representation when the context is novel (Davis et al. 2003; Ploski et al. 2010). In contrast to such inconsistencies, convincing experimental data consistently support a role of hippocampal Zif268 in the contextual fear reconsolidation phase but not in the formation of a new association between shock and context (Lee et al. 2004; Lee 2008). In fact, as previously indicated, long-term consolidation can take place even with global deficits in brain Zif268 (see Lee et al. 2004). Hence, it seems suitable to speculate that Zif268 from the amygdala or from the hippocampus may have a differential role in the emergence of a new association or in the reactivation of an already established trace. Similarly, proteosome-dependent protein degradation in the amygdala has been reported to be critical for fear memory consolidation and reconsolidation in both context and auditory fear procedures (Jarome et al. 2011). However, the infusion of $\beta$-lac into the hippocampus does not seem to affect contextual memory consolidation (Lee et al. 2008). Intra-DH infusion of protein degradation inhibitors blocked memory acquisition using inhibitory avoidance (Lopez-Salon et al. 2001); however, the mechanisms involved in the retention of memory avoidance differ from those implicated in fear conditioning (Wilensky et al. 2000). Moreover, it is noteworthy that no change in the original memory strength is evident after protein degradation blockade when there is no new information to update or when no interfering agent is administered into the $\mathrm{DH}$ or into the amygdala complex associated to recall (Lee 2008; Lee et al. 2008; Jarome et al. 2011).

A likely explanation for the absence of the retrieval-induced updating and reconsolidation mechanism in the DH of stressed rats in the present study could suggest that the emotional state generated by the stressful experience can affect the destabilization and the reconsolidation mechanisms at the time of retrieval. Interestingly, the knockdown of hippocampal Zif268 prior to retrieval in unstressed animals previously subjected to a robust training blocked memory reconsolidation. The fact that similar levels of freezing were exhibited during the retrieval experience between stressed rats and unstressed control animals exposed to a robust conditioning suggests that the different effect observed on fear retention following intra-DH Zif268 ASO cannot be attributed to differences in the degree of fear. Hence, these findings suggest that fear memory from stressed rats is less likely to become destabilized and vulnerable to disruption upon reactivation. Accordingly, retrieval-induced fragility of a contextual fear memory trace was constrained in animals subjected to a stressful situation similar to that used in the current study (Bustos et al. 2010).

In contrast to the lack of effect of intra-DH Zif268 ASO in stressed rats, BDNF hippocampal knockdown mitigated the stress-induced facilitating influence on fear retention. This evidence, coupled with the elevation of hippocampal BDNF level following retrieval in stressed animals, provides a strong support for the involvement of a hippocampal BDNF-dependent mechanism in the contextual fear memory resulting from the interaction of stress and retrieval. This evidence confirms prior findings that endogenous BDNF is required for fear-motivated learning in rats (Rattiner et al. 2004a,b).

Importantly, similar fear values during recall were recorded in stressed animals treated with either the BDNF ASO or the MSO, suggesting that the influence of this antisense is not related to the disruption of freezing performance or to an interference of the retrieval process. Enhanced expression of hippocampal BDNF was suggested to be associated with the consolidation of contextual fear memory (Lee et al. 2004); our data could suggest the involvement of an acquisition process of new aversive information in the resulting memory following stress and retrieval. However, it is generally accepted that consolidation is a process that occurs after memory training and not after memory retrieval. Therefore, the fact that hippocampal BDNF is highly expressed in our paradigm does not necessarily mean that the resulting memory following stress is indicative of consolidation. Further research is required to suggest that the combination of stress and the recall experience initiates a consolidation process. It is relevant to note, however, that extensive research supports a role of hippocampal BDNF in the emergence of long-term memory in various hippocampal-dependent paradigms (Lee et al. 2004; Alonso et al. 2005; Lubin et al. 2008). Consistent with the view of the BDNF role in the emergence of long-term memory, accumulating evidence sustains the pivotal role of this molecule in neuronal plasticity underlying learning and memory (Tyler et al. 2002; Yamada and Nabeshima 2003; Rattiner et al. 2005).

The question that arises is by which potential mechanism could stress be acting to magnify fear expression and fear retention after retrieval? It is well established that the BLA plays a major role in the generation of negative affective states (LeDoux 2000) and in the processing of stress-induced emotional information (Roozendaal et al. 2009). Besides, it was reported that the exposure to a stressful event, similar to the one used in the present study, suppressed the GABAergic inhibitory mechanism in BLA resulting in an unmasked activation of glutamatergic projection neurons recorded $1 \mathrm{~d}$ after 
stress (Rodriguez Manzanares et al. 2005; Isoardi et al. 2007). In fact, stress-induced activation of a local network in BLA reduces the threshold induction of LTP (Rodriguez Manzanares et al. 2005; Sarabdjitsingh et al. 2012), a synaptic plastic process closely associated to the formation of long-term memory (Blair et al. 2001; Pape and Pare 2010). Moreover, emotional arousal results in a persistent enhancement of the spontaneous firing rates of BLA neurons (Pelletier et al. 2005). It was proposed that the reduction of this inhibitory mechanism in BLA enhanced activation of downstream structures implicated in generating a robust emotional response and leading to excessive emotional output to mild aversive stimulation or to stimulus that would normally induce minimal emotional disturbance (Martijena et al. 2002; Calfa et al. 2006; Bignante et al. 2008). What is more, stress and pharmacologically induced decrease of GABAergic neurotransmission, particularly in BLA, enhance the emergence of fear memory (Rodriguez Manzanares et al. 2005; Kim et al. 2012). A logical prediction from all this evidence suggests that the activation of GABAa sites in BLA prior to the environmental challenge would prevent the enhancing effect on the expression and retention of fear following the interaction of stress and recall. In line with this prediction, our results show that intra-BLA MDZ treatment prior to stress attenuates the enhancement of both fear expression and fear retention. As previously suggested (Dudai 2002), the retrieval of a fear memory can be an aversive experience by itself. Therefore, it seems likely to speculate that prior stress can increase the aversive value of the stimuli that define the context when the retrieval experience is performed under a hyperexcitable BLA, as suggested to occur after stress (Martijena et al. 2002; Rodriguez Manzanares et al. 2005; Isoardi et al. 2007). Such an enhancement is expressed by higher freezing scores during both testing trials. Therefore, under the emotional state elicited by stress, the retrieval experience of a weak memory trace previously established becomes a powerful mnemonic enhancer. In line with this argument, it was recently reported that a negative emotional state elicited by the stimulation of the dorsolateral periaqueductal gray prior to retrieval potentiates a fear memory trace previously acquired (Mochny et al. 2012).

Taken together, the present findings show that the stressinduced enhancing influence on the resulting fear memory following retrieval is dependent on a hippocampal BDNF mechanism. The results described in the current study may contribute to the understanding of the mechanisms involved in the emergence of a traumatic memory, a hallmark element of several anxiety-related disorders.

\section{Materials and Methods}

\section{Animals}

Adult male Wistar rats (60 d old, weighing between 280 and 320 g) from a colony established at the Departamento de FarmacologiaIFEC, Facultad de Ciencias Químicas, Universidad Nacional de Córdoba were used. All animals were housed in standard laboratory Plexiglas cages in groups of three per cage. Food and water were available ad libitum. Animals were maintained on a 12-h-light/ dark cycle (lights on at 0700-1900 h) and at a room temperature of $21-23^{\circ} \mathrm{C}$. The protocols used have been approved by the Animal Care Committee of the Facultad de Ciencias Químicas, Universidad Nacional de Córdoba which are consistent with the standards outlined in the NIH Guide for the Care and Use of Laboratory Animals. The number of animals used, as well as their suffering, was kept at the minimum possible needed to accomplish the goals of this study.

\section{Stressor}

Animals were transferred in their own home cages to an experimental room, and placed for $30 \mathrm{~min}$ inside a plastic cylindrical re- strainer fitted close to the body, preventing animal movement except for the tail and the tip of the nose. At the end of the stress session, animals were returned to the colony room. No other subjects were present in the experimental room during stress exposure. This procedure was selected based on previous findings from our laboratory using a similar stress protocol to that used in the current study (Rodriguez Manzanares et al. 2005; Isoardi et al. 2007; Bustos et al. 2010). Retrieval was performed $1 \mathrm{~d}$ after stress exposure. Such an interval was used based on previous data from this laboratory which showed that following this interval stress promotes fear memory formation and enhances anxiety-like behavior (Rodriguez Manzanares et al. 2005; Bignante et al. 2010). Control unstressed animals were transferred to the experimental room, gently handled, and then returned to the colony room.

\section{Conditioning apparatus}

The conditioning chamber was designated as CA and placed in an acoustically isolated separated room maintained at a constant temperature of $21 \pm 2^{\circ} \mathrm{C}$. It was made of a gray plastic wall $(20 \times$ $23 \times 20 \mathrm{~cm}$ ) with a clear lid. The floor consisted of 10 parallel stainless-steel grid bars, each measuring $4 \mathrm{~mm}$ in diameter and spaced $1.5 \mathrm{~cm}$ apart (center to center), enclosed within a sound-attenuating chamber. The grid floor was attached to a scrambled shocker (UgoBasile Biological Research Apparatus) to provide footshock. Illumination was supplied by a $2.5-\mathrm{W}$ whitelight bulb, and the background noise was made available by ventilation fans and the shock scrambler $(55 \mathrm{~dB})$. The nonassociated chamber $(\mathrm{CB})$ was made of wood $(33 \times 25 \times 33 \mathrm{~cm})$ and had lids of transparent plastic, black walls, and a black rubber floor. This procedure was used in order to make the novel context as different as possible from the one originally used during training, and therefore maximize the possibility of obtaining different levels of expression of the acquired memory. Consequently, differences in the expression of learning in these circumstances might be attributable to contextual changes and/or changes regarding the discrete stimuli that define the context. Both chambers were cleaned with $10 \%$ aqueous ethanol solution before and after each session. Experiments were always performed between 1400 and $1600 \mathrm{~h}$ with the experimenters unaware of the treatment condition.

\section{Behavioral procedures}

\section{Contextual fear conditioning}

The procedure used was similar to that used by Maldonado et al. (2011). On the day of the experiment, two groups of rats randomly selected were transported from the housing room, individually placed in the conditioning chamber, and left undisturbed for a 3-min acclimation period (pre-shock period), following by a single unsignaled footshock (0.3 mA, 3-sec duration) (CA-US) or the rats did not receive the unsignaled footshock (CA-noUS). The animals remained in the chamber for an additional $50 \mathrm{sec}$ (post-shock period). At the end of this period, rats were removed and subsequently placed in their home cages. Only a single footshock was given in the conditioning context to elicit a minimal level of freezing, which allowed a potential facilitating influence of the stress treatment on fear memory (Maldonado et al. 2011). In the experiments in which animals were BLA or DH implanted, the intensity of the footshock was $0.5 \mathrm{~mA}$ in order to induce levels of conditioning similar to those exhibited by animals without cannula implantation because chronic cannulation tends to attenuate the expression of conditioned freezing (Fanselow 1980; Lee et al. 2006). For the stronger conditioning procedure (Experiment 4), animals were placed in the conditioning chamber, allowing a 3-min acclimation period followed by three footshocks $(0.5 \mathrm{~mA}, 3-\mathrm{sec}$ duration at an intershock interval of 30 sec). Animals remained in the chamber for an additional 2 min (post-shock period), after which rats were removed and subsequently placed in their home cages (Isoardi et al. 2004; Rodriguez Manzanares et al. 2005; Bustos et al. 2006). 


\section{Immediate footshock deficit}

It is known that in one-trial contextual fear conditioning, the rat displays freezing when given a footshock after a brief acclimation period. However, when animals are not given such an acclimation period and receive an immediate footshock upon entering the context, they do not freeze in a subsequent retention test in the same context, indicating the absence of contextual fear learning. Therefore, animals must have a substantial period of time in the context prior to shock onset for the occurrence of contextual fear conditioning (Landeira-Fernandez et al. 2006). This phenomenon has been defined as immediate footshock deficit. In this case, rats were placed in the context and subjected to a single footshock within $10 \mathrm{sec}$ of entry into the training chamber. After the shock, rats were quickly removed from the context and returned to their home cages.

\section{Test sessions}

Rats were reexposed to CA without shocks for $3 \mathrm{~min}, 2 \mathrm{~d}$ after training (test 1) and $7 \mathrm{~d}$ after training (test 2). Freezing behavior was assessed as a measure of retrieval during test 1 and as a measure of memory retention during test 2 . In order to control for context specificity, animals were conditioned as above and tested for freezing for the same period of time ( $3 \mathrm{~min}$ ) in CB.

One week prior to experiments rats were handled daily for $\sim 15 \mathrm{sec}$ each. The behavior of each rat was continuously videotaped in order to score freezing behavior during the pre-shock and post-shock periods, and during the entire 3-min test sessions, either in CA or CB. The total time spent freezing in each period was quantified (in seconds) using a stopwatch and expressed as the percentage of total time (Bustos et al. 2010). Freezing, a commonly used index of fear in rats (Blanchard and Blanchard 1969; Fanselow 1980), was defined as a total absence of body and head movement except those associated with breathing.

\section{Surgery and intracranial infusions}

Under aseptic conditions, rats were anesthetized with a mixture of ketamine (55 mg/kg, i.p., Ketajects) and xylazine (11 mg/kg i.p., Xyla-Jects) and placed in a stereotaxic instrument (Stoelting). The scalp was incised and retracted, and the head position was adjusted to place bregma and lambda in the same horizontal plane with the incisor bar set at $-3.3 \mathrm{~mm}$. Two stainless-steel guide cannulas were stereotaxically lowered into the BLA (22 gauge, length $12 \mathrm{~mm}$ ) or into the DH (22 gauge, length $9 \mathrm{~mm}$ ) using the following coordinates: BLA, anterior $-2.8 \mathrm{~mm}$, lateral $\pm 5.0 \mathrm{~mm}$, ventral $-6.1 \mathrm{~mm}$; $\mathrm{DH}$, anterior $-3.8 \mathrm{~mm}$, lateral $\pm 2.0 \mathrm{~mm}$, ventral $-2.0 \mathrm{~mm}$ (Paxinos and Watson 1986). These coordinates were established from pilot studies in our laboratory (Rodriguez Manzanares et al. 2005; Calfa et al. 2007). The guide cannulas were secured in place using acrylic cement and two stainless-steel screws were anchored to the skull. Stainless "dummy cannulas" protruding $0.5 \mathrm{~mm}$ beyond the tips were placed inside the guide cannulas to prevent occlusion. Animals were removed from the stereotaxic instrument to recover under a heat lamp and with close supervision. After surgery, animals received a subcutaneous injection of a penicillin/streptomycin suspension to reduce the risk of infections. Animals were gently handled every day, replacing missing dummy cannulas when necessary, and were allowed to recover from surgery for $5-7 \mathrm{~d}$ before the experimental procedures. Microinfusions were made using 33-gauge infusion cannulas that extended $2 \mathrm{~mm}$ beyond the guide cannulas implanted in the BLA or $1 \mathrm{~mm}$ beyond the guide cannulas implanted in the $\mathrm{DH}$. The infusion cannulas were connected via polyethylene tubing (PE 10, Becton Dickinson) to a $10 \mu \mathrm{L}$ microsyringe (Hamilton) mounted on a microinfusion pump (Cole-Parmer 74900-Series).

\section{Drugs and drug administration}

MDZ (GobbiNovag) was diluted in sterile isotonic SAL $(0.9 \% \mathrm{w} / \mathrm{v})$. The proteasome inhibitor $\beta$-lac (Sigma-Aldrich) was dissolved in $2 \% \mathrm{DMSO} / \mathrm{PBS}$ and adjusted to $\mathrm{pH} 7.0-7.4$ with $\mathrm{NaOH}$.
Oligonucleotides (ODNs [Genbiotech]) were PAGE-purified phosphorothioate end-capped 18-mer sequences and resuspended in sterile PBS. These were BDNF antisense ODN (BDNF ASO), 5'-TCTTCCCCTTTTAATGGT-3'; BDNF missense ODN (BDNF MSO), 5'-ATACTTTCTGTTCTTGCC-3'; Zif268 antisense ODN (Zif268 ASO), 5'- GGTAGTTGTCCATGGTGG-3'; and Zif268 missense ODN (Zif268 MSO), 5'-GTGTTCGGTAGGGTGTCA-3'.

For intra-BLA infusion, each rat was bilaterally infused with $0.5 \mu \mathrm{L}$ per side of MDZ $(1 \mu \mathrm{g} / \mu \mathrm{L})$ or SAL into BLA at a flow rate of $0.5 \mu \mathrm{L} / \mathrm{min}$ over a period of $60 \mathrm{sec}$ (Rodriguez Manzanares et al. 2005). This dose of MDZ was selected based on previous studies which showed that this dose was effective to attenuate stress-induced effects on fear memory formation (Rodriguez Manzanares et al. 2005). $\beta$-lac (32 ng/ $\mu \mathrm{L}$ ) was bilaterally infused in $\mathrm{DH}(1 \mu \mathrm{L}$ per side, $0.5 \mu \mathrm{L} / \mathrm{min})$ at the same dose reported by Lee (2008) and Lee et al. (2008). The doses and rate of infusion of ODNs were selected based on previous research (Lee et al. 2004; Bekinschtein et al. 2007; Lee 2008). These authors have shown an important diffusion of the ODNs into the $\mathrm{DH}$ and slightly into the overlying cortex. Zif268 $(2 \mathrm{nmol} / \mu \mathrm{L})$ and BDNF $(2 \mathrm{nmol} / \mu \mathrm{L})$ ODNs were bilaterally infused in DH 90 min prior to test $1(1.0 \mu \mathrm{L}$ per side; $0.125 \mu \mathrm{L} / \mathrm{min}$ ) (Lee 2008$)$.

In all cases, after completion of the volume injection, the infusion cannulas were kept in place for an additional period of 120 sec to allow diffusion of the drug.

\section{ELISA}

Animals were individually transferred to a separate room for sacrifice. Their brains were quickly removed and placed in an acrylic brain matrix (Stoelting) on ice. Coronal brain slices of $1 \mathrm{~mm}$ containing the hippocampus were prepared, and the DH was micropunched (Paxinos and Watson 1986). Tissue punches were homogenized in $300 \mathrm{~mL}$ of lysis buffer $(137 \mathrm{mM} \mathrm{NaCl}, 20 \mathrm{mM}$ Tris-HCl [pH 8.0], 1\% NP40, 10\% glycerol, $1 \mathrm{mM}$ phenylmethylsulfonylfluoride) containing protease inhibitors $(10 \mu \mathrm{g} / \mathrm{mL}$ aprotinin, $1 \mu \mathrm{g} / \mathrm{mL}$ leupeptin) and phosphatase inhibitor $(0.5 \mathrm{mM}$ sodium orthovanadate). Tissue and lysis buffer were incubated on ice for $15 \mathrm{~min}$ and centrifuged at $12,000 \mathrm{~g}$ for $10 \mathrm{~min}$ at $4^{\circ} \mathrm{C}$. The supernatant was collected and total protein concentrations were determined using the DC Protein Assay (Bio-Rad). BDNF was measured using the BDNF ELISA Emax Immunoassay System (Promega) as per the manufacturer's instructions. BDNF levels were determined relative to a standard curve constructed from measures of kit-supplied BDNF protein standards $(0-500$ pg of BDNF protein) that were assayed simultaneously with the experimental samples. BDNF levels are expressed as picograms of BDNF per milligram of sample protein.

\section{Histological procedures}

After behavioral tests, rats were sacrificed by an overdose of chloral hydrate and their brains were removed and immersed in a $4 \%$ formalin fixative solution. Frontal sections were cut in a cryostat (Leica). An observer blinded to the experimental condition verified cannula placement throughout the BLA and DH under a light microscope. Animals with inaccurate cannula placement or extensive damage were excluded from data analysis.

\section{Statistical analyses}

The results are expressed as the mean \pm S.E.M. Behavioral and biochemical data were analyzed using Student's $t$-test or ANOVAS. In the latter case, the source of the main significant effects or interactions was determined by Bonferroni's protected least significant difference (PLSD) post-hoc multiple comparisons test. The significance level used for all statistical analyses was set at $P<0.05$.

\section{Acknowledgments}

M.G. thanks CONICET. This research was supported by grants from MinCyT-Córdoba, SECYT-UNC, CONICET, and Agencia Nacional de Promoción Científica y Tecnológica-FONCYT 
(Argentina) to V.A.M. We would like to thank Estela Salde for technical assistance and Dolores Trebucq for English technical assistance.

\section{References}

Alberini CM. 2005. Mechanisms of memory stabilization: Are consolidation and reconsolidation similar or distinct processes? Trends Neurosci 28: $51-56$.

Alberini CM. 2011. The role of reconsolidation and the dynamic process of long-term memory formation and storage. Front Behav Neurosci 5: 12.

Alonso M, Bekinschtein P, Cammarota M, Vianna MR, Izquierdo I, Medina JH. 2005. Endogenous BDNF is required for long-term memory formation in the rat parietal cortex. Learn Mem 12: 504-510.

Atsak P, Hauer D, Campolongo P, Schelling G, McGaugh JL, Roozendaal B. 2012. Glucocorticoids interact with the hippocampal endocannabinoid system in impairing retrieval of contextual fear memory. Proc Natl Acad Sci 109: 3504-3509.

Bekinschtein P, Cammarota M, Igaz LM, Bevilaqua LR, Izquierdo I Medina JH. 2007. Persistence of long-term memory storage requires a late protein synthesis- and BDNF-dependent phase in the hippocampus. Neuron 53: 261-277.

Bignante EA, Rodriguez Manzanares PA, Mlewski EC, Bertotto ME, Bussolino DF, Paglini G, Molina VA. 2008. Involvement of septal Cdk5 in the emergence of excessive anxiety induced by stress. Eur Neuropsychopharmacol 18: 578-588.

Bignante EA, Paglini G, Molina VA. 2010. Previous stress exposure enhances both anxiety-like behaviour and p35 levels in the basolateral amygdala complex: Modulation by midazolam. Eur Neuropsychopharmacol 20: 388-397.

Blair HT, Schafe GE, Bauer EP, Rodrigues SM, LeDoux JE. 2001. Synaptic plasticity in the lateral amygdala: A cellular hypothesis of fear conditioning. Learn Mem 8: 229-242.

Blanchard RJ, Blanchard DC. 1969. Crouching as an index of fear. J Comp Physiol Psychol 67: 370-375.

Bustos SG, Maldonado H, Molina VA. 2006. Midazolam disrupts fear memory reconsolidation. Neuroscience 139: 831-842.

Bustos SG, Giachero M, Maldonado H, Molina VA. 2010. Previous stress attenuates the susceptibility to midazolam's disruptive effect on fear memory reconsolidation: Influence of pre-reactivation D-cycloserine administration. Neuropsychopharmacology 35: 1097-1108.

Cai WH, Blundell J, Han J, Greene RW, Powell CM. 2006. Postreactivation glucocorticoids impair recall of established fear memory. J Neurosci 26: 9560-9566.

Calfa G, Volosin M, Molina VA. 2006. Glucocorticoid receptors in lateral septum are involved in the modulation of the emotional sequelae induced by social defeat. Behav Brain Res 172: 324-332.

Calfa G, Bussolino D, Molina VA. 2007. Involvement of the lateral septum and the ventral hippocampus in the emotional sequelae induced by social defeat: Role of glucocorticoid receptors. Behav Brain Res 181: $23-34$.

Cordero MI, Venero C, Kruyt ND, Sandi C. 2003. Prior exposure to a single stress session facilitates subsequent contextual fear conditioning in rats. Horm Behav 44: 338-345.

Davis HP, Squire LR. 1984. Protein synthesis and memory: A review. Psychol Bull 96: 518-559.

Davis S, Bozon B, Laroche S. 2003. How necessary is the activation of the immediate early gene zif268 in synaptic plasticity and learning? Behav Brain Res 142: $17-30$.

Debiec J, LeDoux JE, Nader K. 2002. Cellular and systems reconsolidation in the hippocampus. Neuron 36: 527-538

de Quervain DJ, Roozendaal B, McGaugh JL. 1998. Stress and glucocorticoids impair retrieval of long-term spatial memory. Nature 394: $787-790$.

de Quervain DJ, Henke K, Aerni A, Treyer V, McGaugh JL, Berthold T, Nitsch RM, Buck A, Roozendaal B, Hock C. 2003.

Glucocorticoid-induced impairment of declarative memory retrieval is associated with reduced blood flow in the medial temporal lobe. Eur $J$ Neurosci 17: 1296-1302.

Dudai Y. 2002. Memory from A to Z. Keywords, concepts and beyond. Oxford University Press, Oxford.

Dudai Y. 2004. The neurobiology of consolidations, or, how stable is the engram? Annu Rev Psychol 55: 51-86.

Dudai Y. 2006. Reconsolidation: The advantage of being refocused. Curr Opin Neurobiol 16: 174-178.

Duvarci S, Nader K. 2004. Characterization of fear memory reconsolidation. J Neurosci 24: 9269-9275.

Fanselow MS. 1980. Conditioned and unconditional components of post-shock freezing. Pavlov I Biol Sci 15: 177-182.

Gisquet-Verrier P, Riccio DC. 2012. Memory reactivation effects independent of reconsolidation. Learn Mem 19: 401-409.
Goelet P, Castellucci VF, Schacher S, Kandel ER. 1986. The long and the short of long-term memory-a molecular framework. Nature 322 419-422.

Hall J, Thomas KL, Everitt BJ. 2000. Rapid and selective induction of BDNF expression in the hippocampus during contextual learning. Nat Neurosci 3: $533-535$.

Hall J, Thomas KL, Everitt BJ. 2001. Cellular imaging of zif268 expression in the hippocampus and amygdala during contextual and cued fear memory retrieval: Selective activation of hippocampal CA1 neurons during the recall of contextual memories. J Neurosci 21: 2186-2193.

Hardt O, Einarsson EO, Nader K. 2010. A bridge over troubled water: Reconsolidation as a link between cognitive and neuroscientific memory research traditions. Annu Rev Psychol 61: 141-167.

Hupbach A, Gomez R, Nadel L. 2009. Episodic memory reconsolidation: Updating or source confusion? Memory 17: 502-510.

Isoardi NA, Martijena ID, Carrer HF, Molina VA. 2004. Increased fear learning coincides with neuronal dysinhibition and facilitated LTP in the basolateral amygdala following benzodiazepine withdrawal in rats. Neuropsychopharmacology 29: 1852-1864.

Isoardi NA, Bertotto ME, Martijena ID, Molina VA, Carrer HF. 2007. Lack of feedback inhibition on rat basolateral amygdala following stress or withdrawal from sedative-hypnotic drugs. Eur J Neurosci 26: 1036-1044.

Jarome TJ, Werner CT, Kwapis JL, Helmstetter FJ. 2011. Activity dependent protein degradation is critical for the formation and stability of fear memory in the amygdala. PloS One 6: e24349.

Kida S, Josselyn SA, Pena de Ortiz S, Kogan JH, Chevere I, Masushige S, Silva AJ. 2002. CREB required for the stability of new and reactivated fear memories. Nat Neurosci 5: 348-355.

Kim DH, Kim JM, Park SJ, Cai M, Liu X, Lee S, Shin CY, Ryu JH. 2012. GABA(A) receptor blockade enhances memory consolidation by increasing hippocampal BDNF levels. Neuropsychopharmacology 37: $422-433$.

Landeira-Fernandez J, DeCola JP, Kim JJ, Fanselow MS. 2006. Immediate shock deficit in fear conditioning: Effects of shock manipulations. Behav Neurosci 120: $873-879$.

LeDoux JE. 2000. Emotion circuits in the brain. Annu Rev Neurosci 23: $155-184$.

Lee JL. 2008. Memory reconsolidation mediates the strengthening of memories by additional learning. Nat Neurosci 11: 1264-1266.

Lee JL. 2009. Reconsolidation: Maintaining memory relevance. Trends Neurosci 32: 413-420.

Lee JL. 2010. Memory reconsolidation mediates the updating of hippocampal memory content. Front Behav Neurosci 4: 168.

Lee JL, Everitt BJ, Thomas KL. 2004. Independent cellular processes for hippocampal memory consolidation and reconsolidation. Science 304: $839-843$.

Lee JL, Milton AL, Everitt BJ. 2006. Reconsolidation and extinction of conditioned fear: Inhibition and potentiation. J Neurosci 26: $10051-10056$

Lee SH, Choi JH, Lee N, Lee HR, Kim JI, Yu NK, Choi SL, Kim H, Kaang BK. 2008. Synaptic protein degradation underlies destabilization of retrieved fear memory. Science 319: 1253-1256.

Lopez-Salon M, Alonso M, Vianna MR, Viola H, Mello e Souza T, Izquierdo I, Pasquini JM, Medina JH. 2001. The ubiquitin-proteasome cascade is required for mammalian long-term memory formation. Eur J Neurosci 14: $1820-1826$.

Lubin FD, Roth TL, Sweatt JD. 2008. Epigenetic regulation of BDNF gene transcription in the consolidation of fear memory. J Neurosci 28: $10576-10586$

Maddox SA, Monsey MS, Schafe GE. 2011. Early growth response gene 1 (Egr-1) is required for new and reactivated fear memories in the lateral amygdala. Learn Mem 18: 24-38.

Maldonado NM, Martijena ID, Molina VA. 2011. Facilitating influence of stress on the consolidation of fear memory induced by a weak training. Reversal by midazolam pretreatment. Behav Brain Res 225: 77-84.

Malkani S, Rosen JB. 2000. Specific induction of early growth response gene 1 in the lateral nucleus of the amygdala following contextual fear conditioning in rats. Neuroscience 97: 693-702.

Martijena ID, Rodriguez Manzanares PA, Lacerra C, Molina VA. 2002. Gabaergic modulation of the stress response in frontal cortex and amygdala. Synapse 45: 86-94.

McGaugh JL. 2000. Memory-a century of consolidation. Science 287: $248-251$.

Miller CA, Sweatt JD. 2006. Amnesia or retrieval deficit? Implications of a molecular approach to the question of reconsolidation. Learn Mem 13 498-505.

Mochny CR, Kincheski GC, Molina VA, Carobrez AP. 2012. Dorsolateral periaqueductal gray stimulation prior to retrieval potentiates a contextual fear memory in rats. Behav Brain Res 237C: 76-81.

Nader K. 2003. Memory traces unbound. Trends Neurosci 26: 65-72. 
Nader K, Schafe GE, Le Doux JE. 2000. Fear memories require protein synthesis in the amygdala for reconsolidation after retrieval. Nature 406: $722-726$.

Pape HC, Pare D. 2010. Plastic synaptic networks of the amygdala for the acquisition, expression, and extinction of conditioned fear. Physiol Rev 90: $419-463$.

Paxinos G, Watson C. 1986. The rat brain in stereotaxic coordinates. Academic Press, San Diego, CA.

Payne JD, Jackson ED, Hoscheidt S, Ryan L, Jacobs WJ, Nadel L. 2007. Stress administered prior to encoding impairs neutral but enhances emotional long-term episodic memories. Learn Mem 14: 861-868.

Pelletier JG, Likhtik E, Filali M, Pare D. 2005. Lasting increases in basolateral amygdala activity after emotional arousal: Implications for facilitated consolidation of emotional memories. Learn Mem 12: 96-102.

Ploski JE, Park KW, Ping J, Monsey MS, Schafe GE. 2010. Identification of plasticity-associated genes regulated by Pavlovian fear conditioning in the lateral amygdala. I Neurochem 112: 636-650.

Rattiner LM, Davis M, French CT, Ressler KJ. 2004a. Brain-derived neurotrophic factor and tyrosine kinase receptor B involvement in amygdala-dependent fear conditioning. J Neurosci 24: 4796-4806.

Rattiner LM, Davis M, Ressler KJ. 2004b. Differential regulation of brain-derived neurotrophic factor transcripts during the consolidation of fear learning. Learn Mem 11: 727-731.

Rattiner LM, Davis M, Ressler KJ. 2005. Brain-derived neurotrophic factor in amygdala-dependent learning. Neuroscientist 11: 323-333.

Rodriguez Manzanares PA, Isoardi NA, Carrer HF, Molina VA. 2005. Previous stress facilitates fear memory, attenuates GABAergic inhibition, and increases synaptic plasticity in the rat basolateral amygdala. J Neurosci 25: 8725-8734.

Rodriguez-Ortiz CJ, Garcia-DeLaTorre P, Benavidez E, Ballesteros MA, Bermudez-Rattoni F. 2008. Intrahippocampal anisomycin infusions disrupt previously consolidated spatial memory only when memory is updated. Neurobiol Learn Mem 89: 352-359.

Roozendaal B. 2002. Stress and memory: Opposing effects of glucocorticoids on memory consolidation and memory retrieval. Neurobiol Learn Mem 78: 578-595.

Roozendaal B, McEwen BS, Chattarji S. 2009. Stress, memory and the amygdala. Nat Rev Neurosci 10: 423-433.

Rudy JW. 2008. Destroying memories to strengthen them. Nat Neurosci 11: $1241-1242$.

Sara SJ. 2000. Retrieval and reconsolidation: Toward a neurobiology of remembering. Learn Mem 7: 73-84.

Sarabdjitsingh RA, Kofink D, Karst H, de Kloet ER, Joels M. 2012. Stress-induced enhancement of mouse amygdalar synaptic plasticity depends on glucocorticoid and ss-adrenergic activity. PloS One 7: e42143.

Schiller D, Monfils MH, Raio CM, Johnson DC, Ledoux JE, Phelps EA. 2010. Preventing the return of fear in humans using reconsolidation update mechanisms. Nature 463: 49-53.

Tronson NC, Taylor JR. 2007. Molecular mechanisms of memory reconsolidation. Nat Rev Neurosci 8: 262-275.

Tyler WJ, Alonso M, Bramham CR, Pozzo-Miller LD. 2002. From acquisition to consolidation: On the role of brain-derived neurotrophic factor signaling in hippocampal-dependent learning. Learn Mem 9: 224-237.

Wilensky AE, Schafe GE, LeDoux JE. 2000. The amygdala modulates memory consolidation of fear-motivated inhibitory avoidance learning but not classical fear conditioning. J Neurosci 20: 7059-7066.

Yamada K, Nabeshima T. 2003. Brain-derived neurotrophic factor/TrkB signaling in memory processes. J Pharmacol Sci 91: 267-270.

Received November 5, 2012; accepted in revised form February 3, 2013. 


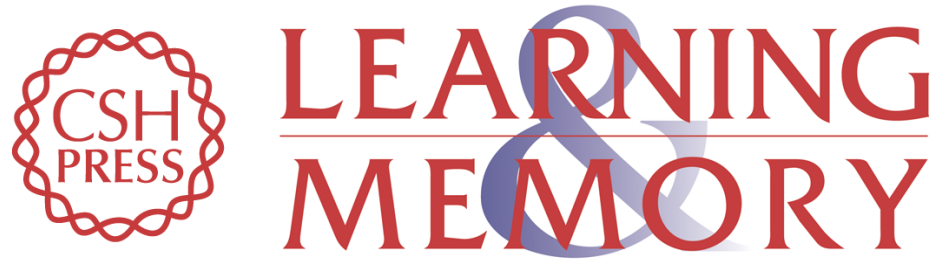

\section{A BDNF sensitive mechanism is involved in the fear memory resulting from the interaction between stress and the retrieval of an established trace}

Marcelo Giachero, Silvia G. Bustos, Gaston Calfa, et al.

Learn. Mem. 2013, 20:

Access the most recent version at doi:10.1101//m.029306.112

References This article cites 73 articles, 21 of which can be accessed free at: http://learnmem.cshlp.org/content/20/5/245.full.html\#ref-list-1

License

Email Alerting

Receive free email alerts when new articles cite this article - sign up in the box at the Service top right corner of the article or click here. 